\title{
Survival analysis of children and adolescents with melanoma
}

\section{Análise de sobrevida no melanoma infantojuvenil}

Kátia Sheylla Malta Purim ${ }^{1}$ (D); Murilo Valandro de-Práp; Debora Cavasin Bahr ${ }^{1}$; Gabriel Seijl Hayakawa ${ }^{1}$; Giulia Herek Rossi ${ }^{1}$; Lucas de Paula SoARes ${ }^{1}$.

\section{A B S T R A C T}

\begin{abstract}
Objectives: to analyze the survival in juvenile melanoma. Methods: retrospective study conducted by hospital record review and cancer records of patients aged 0 to 19 years, with histologically proven melanoma and treated between 1997 and 2017 at the Erasto Gaertner Hospital in Curitiba-PR. Results: the sample comprised 24 patients, female (62.5\%), mean $14.14 \pm 4.72$ years old, with head and neck melanoma (37.5\%), chest (25\%) and extremities. (20.8\%). Signs and symptoms at diagnosis were increased lesion size (25\%), bleeding (20.8\%) and pruritus (16.6\%). There was a Breslow II and IV index and Clark IV level, with a statistical tendency between Breslow IV and death $(p=0.127)$, and significance between Clark $V$ and death $(p=0.067)$. Nine $(37.5 \%)$ patients had metastases, six $(25 \%)$ with distant metastases died $(p=0.001)$, five were girls $(20.8 \%)$. Surgery was the standard treatment and chemotherapy the most used adjuvant (37.5\%). The average time between diagnosis and death was $1.3 \pm 1.2$ years and survival were $3.7 \pm 3.2$ years. Conclusion: there was a delay in diagnosis, high morbidity and mortality and average survival less than five years.
\end{abstract}

Keywords: Melanoma. Child. Sentinel Lymph Node. Survival Analysis.

\section{INTRODUCTION}

$C$ urrently, melanoma corresponds to less than 3\% of all malignancies in individuals under 20 years old, but it is the most common solid tumor between 15 and 29 years old ${ }^{1,2}$. Development is influenced by individual factors (male sex, atypical, congenital, large, numerous, or rapidly growing dysplastic nevi, pigmented xeroderma, light skin and eyes, history of cancer or premalignant skin lesions, solid organ or hematopoietic cell transplants, HIV/AIDS, and family history of melanoma) and environmental or modifiable factors (artificial tanning, living close to the Equator, inadequate exposure to solar radiation, and sunburn $)^{2,3}$.

Children can develop melanoma without meeting the conventional $A B C D E$ criteria $(A=$ asymmetry, $\mathrm{B}=$ uneven border, $\mathrm{C}=$ varied color, $\mathrm{D}=$ diameter $>$ $6 \mathrm{~mm}, \mathrm{E}=$ elevation$^{3}$ and without a strong correlation with sunburn ${ }^{4}$.

Infantile-juvenile melanoma, classified as superficial spreading (more frequent), nodular, lentigo maligna and acral lentiginous ${ }^{5,6}$, has a tendency to atypical forms and locations ${ }^{1,3,5}$. Lesion growth, irregularity of edges and colors, inflammation, and exudation rise suspicion ${ }^{3,5}$. The diagnosis requires skin biopsy and histopathological study to differentiate from benign and malignant pigmented lesions, determine thickness (Breslow Index and Clark's level), perform staging, and institute therapy.

In the prepubertal age group (age $\leq 11$ years), sentinel lymph node positivity is more frequent, the Breslow Index and Clark level are higher, but survival indicators are better when compared with adolescents (age $\geq 11$ years) $)^{1,3,6}$. Regardless of the age group, melanoma has the potential for aggression and metastasis to the lymphatic system, skin, brain, and lungs

Metastases are associated with delayed diagnosis and reduction in the survival curve to down to $10 \%$ in five years ${ }^{7}$. Surgical treatment must remove the tumor and previously defined margins, according to staging. Sentinel lymph node biopsy is indicated for Breslow indexes $\geq 0.75 \mathrm{~mm}$, Clark IV-V levels, mitotic

1 - Universidade Positivo, Curso de Medicina - Curitiba - PR - Brasil 
index $\geq 5 / \mathrm{mm}^{2}$, and absence of tumor regression ${ }^{3,6,7}$.

TNM staging considers the Breslow Index, presence of ulcerations, lymph node involvement, and location of distant metastases ${ }^{2,8}$. The prognosis tends to be better in patients with in situ tumors, absence of ulcerations and metastases, low Breslow index and Clark level, and negativity in the investigation of sentinel lymph node ${ }^{1,6,8}$. The Brazilian literature is scarce in terms of melanoma in children and adolescents.

\section{METHODS}

We retrospective analyzed the profile of melanoma and the survival of patients aged 0 to 19 years, attended between January 1997 and October 2017, at the Hospital Erasto Gaertner, in Curitiba, state of Paraná, Brazil. The project involved reviewing medical records and was approved by the Ethics in Research Committee of the insitution (CEP HEG - CAAE: 89962518.0.0000.0098).

Inclusion criteria were a histologically proven diagnosis of melanoma and age under 19 years old. We excluded patients with incomplete data (except histological type, Breslow index and (lark level). To determine the patients' epidemiological profile we assessed sex, age, Breslow Index, Clark level, presence of ulceration, family history of melanoma, occurrence of metastasis, site of metastasis, and histological type. For the construction of the survival curve, we used the death date in the medical record as the outcome definition.

The Breslow Index ${ }^{2}$ is classically used as a determining factor for staging, prognosis, and treatment, and evaluates the tumor depth $(T)$ in millimeters, classifying it as Tis (tumor in situ), TI $(<0.75 \mathrm{~mm}), \mathrm{TIl}(0.75$ $1.5 \mathrm{~mm})$, TIII (1.5 $3.0 \mathrm{~mm})$, TIV $(3.04 .0 \mathrm{~mm})$ and TV (> 4.0 $\mathrm{mm})$. The Clark Level ${ }^{2}$ describes the neoplastic invasion of the skin at levels I (only the epidermis), II (epidermis and part of the papillary dermis), III (papillary dermis), IV (reticular dermis), and $\mathrm{V}$ (hypodermis).

We expressed continuous variables as mean \pm standard deviation and compared them with the Chisquare and Fisher's Exact tests, as appropriate, with the aid of the SPSS software, considering $p<0.05$. We used the Kaplan-Meier method for the survival curves, followed by univariate analysis for prognostic factors using the Log Rank, Breslow and Tarone-Ware tests.

\section{RESULTS}

There were 29 cases of melanoma in children and teens under 19 years of age during the study period. Five records were unsuitable for collection. The sample consisted of 24 patients, of whom $62.5 \%$ were female, the average age group of $14.12 \pm 4.72$ years, with predominance of head and neck lesions (41.7\%). There was one patient with Xeroderma Pigmentosa and one with a family history of cutaneous melanoma. We did not observe dysplastic nevus syndrome or congenital melanocytic nevus. There were no data on photo exposure and sunburn.

Sentinel Lymph Node Biopsy was performed in 16 patients (66.8\%) and margin enlargement in 14 (58.3\%). Seven patients (31.8\%) had ulceration of the primary lesion, five $(20.8 \%)$, peritumoral lymphocytic infiltration, and three (13.6\%), margin involvement.

The signs and symptoms at diagnosis were increased lesion size in nine cases $(37.5 \%)$, bleeding in five $(20.8 \%)$, pruritus in four $(16.6 \%)$, color change in two (8.3\%), pain in two (8.3\%), and other manifestations in 25 (asthenia, weight loss, etc.).

We found Breslow Indexes II (35.3\%) and IV (29.4\%) and Clark Level IV (43.8\%), with a trend between Breslow IV and death $(p=0.127)$ and significance between Clark V and death $(p=0.067)$. In seven records $(29.1 \%)$ there was no Breslow or Clark data and in 11 (47.8\%) the classification of melanoma was missing. Of the 12 cases with histological type records, six (26.08\%) were superficial spreading melanoma (Table 1).

Nine patients (37.5\%) had metastatic disease ( $p$ $=0.001$ ); in two cases only the lymph node was affected. Metastasis sites were lymph nodes in seven (29.2\%) patients, lung in three $(12.5 \%)$, central nervous system in three $(12.5 \%)$, and liver (4.2\%), spleen (4.2\%), and bones $(4.2 \%)$ in one case each. All six cases with metastases in the cephalic region $(25 \%)$ died $(p=0.001)$, five of whom were girls.

Chemotherapy was the adjuvant treatment in nine cases $(37.5 \%)$; in two patients, it was associated with radiotherapy, and in one, with immunotherapy. The average time between diagnosis and death was $1.3 \pm 1.2$ years. The average survival was $3.70 \pm 3.24$ years.

Survival distribution (Kaplan-Meier) was 
statistically significant $(p=0.01)$ according to the Clark Level (Figure 1), unlike what happened with the Breslow Index (Figure 2) and the presence of ulceration (Figure 3).

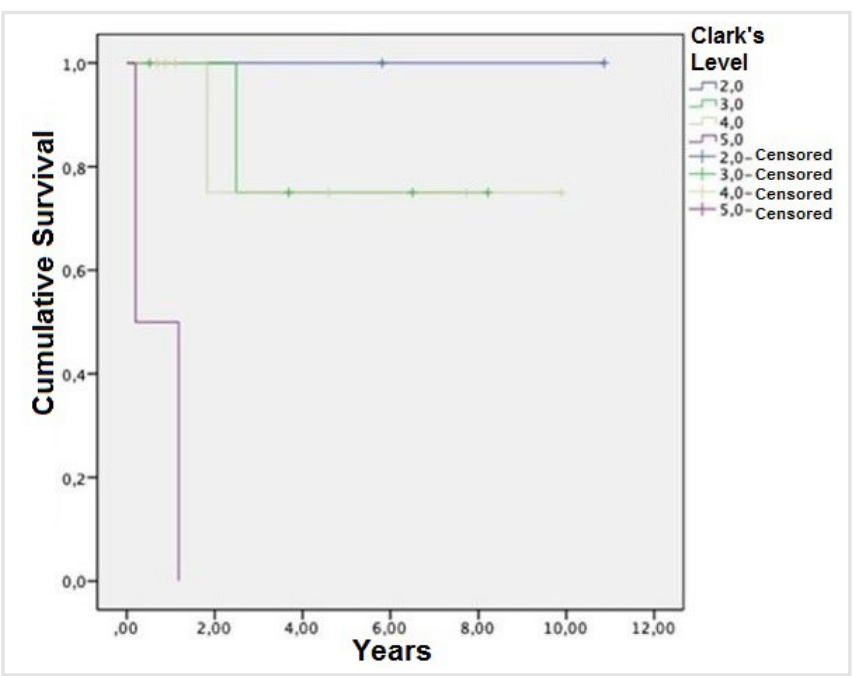

Figure 1. Analysis of survival and Clark's level.

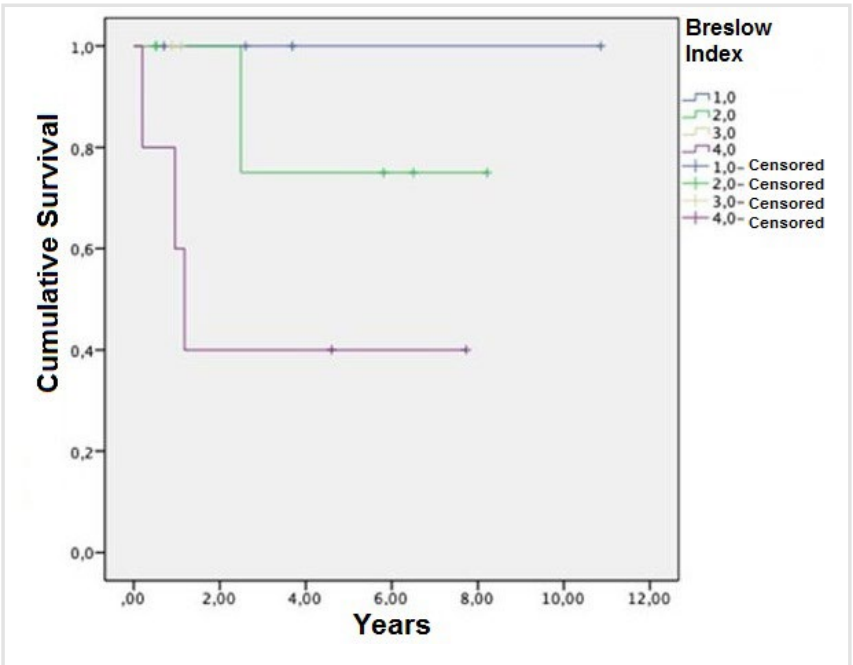

Figure 2. Analysis of survival and Breslow index in children and adolescents melanoma.

As for the associated comorbidities, one patient had asthma and survived, while the other two died, one with congenital heart disease associated with systemic arterial hypertension and another with acute lymphoid leukemia.

\section{DISCUSSION}

Although the incidence of melanoma in children and adolescents has increased in recent decades ${ }^{8,9}$, it is considered rare in these age groups, especially among prepubertal individuals ${ }^{7-11}$. This first Brazilian historical series of childhood and juvenile melanoma (1997-2017) confirms this rarity, since only four cases occurred in the first decade of life.

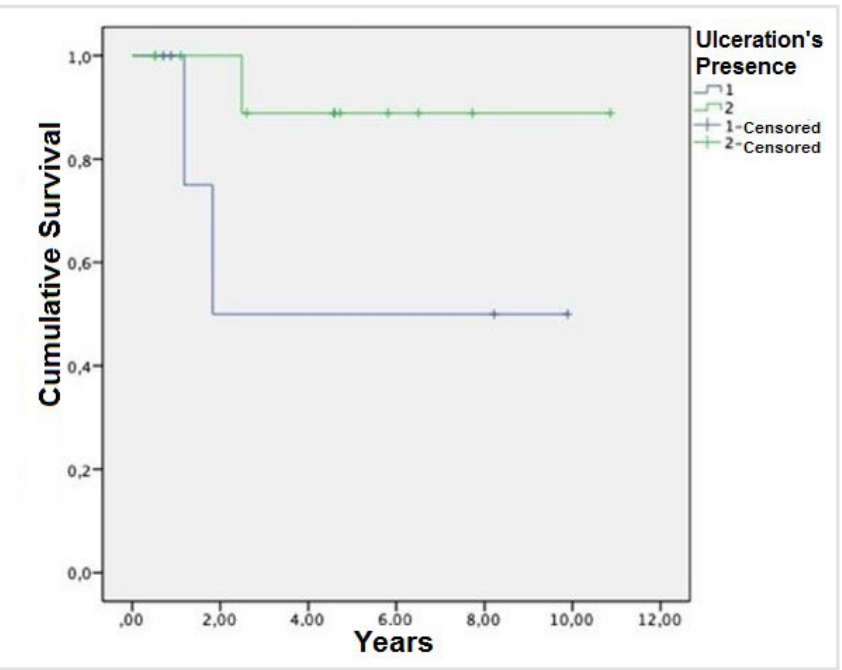

Figure 3. Analysis of survival and presence of ulceration in children-adolescents melanoma.

Melanoma lesions affecting girls (62.5\%) and located on the head and neck (41.7\%), limbs (25\%) and trunk $(20.8 \%)$ contrast with the literature that points to a similar incidence between boys and girls and higher frequency in limbs (40\%), chest (35\%), and head and neck $(17 \%)^{9}$.

Clinical manifestations, such as increased lesions, pruritus, and bleeding were similar to the literature ${ }^{8}$. However, they may go unnoticed or hidden. Health professionals and parents / guardians must beware of skin lesions in children and adolescents with such characteristics, or with unusual aspects ${ }^{3}$, so as not to delay the detection and treatment of a possible cancer.

Regarding the histological classification, among the specified tumor types, superficial spreading melanoma predominated, followed by nodular and acral / mucous (Table 1), corroborating studies in the pediatric ${ }^{4,11-13}$ and general ${ }^{2,14}$ populations.

The degree of invasion prevalent at diagnosis was of Breslow Indexes II and IV and Clark level IV (Table 1). Researches in this age group show a higher frequency of diagnosis of Clark's level IV4,11, while in the general population there is a tendency for Clark's level lower than ${ } I^{13}$. These data point to the possibility of a later diagnosis of melanoma in children and adolescents when compared with adults ${ }^{15}$. 
Table 1. Characteristics of children and adolescents melanoma.

Relative Frequency (\%)

\begin{tabular}{lcc}
\hline Breslow & I & $4(23.5)$ \\
index & II & $6(35.3)$ \\
& III & $2(11.8)$ \\
& IV & $5(29.4)$ \\
& & $\mathrm{P}=0.127$ \\
\hline Clark's level & I & 0 \\
& II & $2(12.5)$ \\
& III & $5(31.3)$ \\
& IV & $7(43.8)$ \\
& V & $5(12.5)$ \\
Ulceration & Yes & $7(35)$ \\
& No & $13(65)$ \\
& & $\mathrm{P}=0.270$ \\
Histological & Acral lentiginous & $3(12.5)$ \\
types & Superficial & $6(25)$ \\
& spreading & $3(12.5)$ \\
& Nodular & \\
\hline Anatomic & Head & $10(41.7)$ \\
site & Trunk & $5(20.8)$ \\
& Limbs & $6(25)$ \\
& Hands and feet & $3(12.5)$
\end{tabular}

A classic study by Saenz et al. (1999) ${ }^{8}$ demonstrated that all patients with melanomas of thickness $\leq 1 \mathrm{~mm}$ had a survival greater than 10 years. In the research by Averbook et al. (2013) with melanomas measuring $\leq 1 \mathrm{~mm}$ in thickness had a favorable prognosis, but when they measured $>1-2 \mathrm{~mm}$, the survival rate, despite similar, decreased.

Tumor thickness and ulceration are strong predictors of sentinel lymph node metastasis in children $^{6,16,17}$. Young people with melanoma with a Breslow Index greater than I and a negative sentinel node had $100 \%$ survival, while in those with a positive node the survival dropped to $89 \%$, indicating that positive sentinel node is associated with an unfavorable prognosis ${ }^{17}$.

We observed a statistical trend for a lower survival rate from Clark's level IV and a strong relationship for level $V$. It was not possible to find a statistical relationship between reduced survival and higher Breslow indexes, nor with the presence of ulceration, due to the small sample size and absence of such records.

All patients in this sample underwent an excisional biopsy. In nine cases (37.5\%), there was a regional or distant metastasis, consistent with investigations in this age group ${ }^{1,11}$. A research revealed that in patients with distant metastases ${ }^{11}$, the majority affected more than one site, the involved organs being the lungs, central nervous system, bones, and liver. We found a similar pattern of metastases plus involvement of the spleen.

Although there are no specific guidelines for the treatment of melanoma in children ${ }^{12}$, the surgical approach was complemented with chemotherapy, radiotherapy, and adjuvant immunotherapy, when relevant. In agreement with the literature', patients with distant metastases died during follow-up. A study analyzing survival in pediatric melanoma ${ }^{6}$ showed that in metastatic cases the average survival time was less than one year, and the overall 5 -year survival was less than $12 \%$.

The disease relapsed in four cases (16.6\%) in the present sample, similar to the research by Ferrari et al. $(2014)^{11}$, in which 10 of the 54 patients $(18.5 \%)$ had recurrence related to metastatic forms of melanoma. Studies show a variation in global melanoma mortality from $10 \%$ to $41 \%$ in populations up to 21 years of age $\mathrm{e}^{1,8}$.

In the present investigation, six patients (25\%) died during follow-up, with poorer survival in girls and in patients with comorbidities (congenital heart disease / hypertension, and acute lymphoid leukemia). Tumor subtype, biology, hormonal influence, lymph node status, among others are important prognostic factors in melanoma in childhood and adolescence ${ }^{18,19}$. Probably the significant failure rates in the treatment of metastatic neoplasia occurred due to the progress of the disease, influenced by population characteristics and available resources ${ }^{7,18}$.

This study has limitations due to the retrospective design and incomplete records. However, it contributes with knowledge about the epidemiological and pathological profile of childhood and juvenile melanoma, alerts about the need for early detection to improve prognosis, to maximize quality of life, and to minimize complications and costs, and encourages appropriate referral to the oncology service. 


\section{CONCLUSION}

Melanoma was detected in females, aged
$14.12 \pm 4.72$ years, Breslow II and IV indexes, Clark IV level, with high metastatic potential and mean survival of $3.7 \pm 3.2$ years.

\title{
R E S U M O
}

\begin{abstract}
Objetivos: analisar a sobrevida no Melanoma Infantojuvenil. Métodos: estudo retrospectivo realizado mediante revisão de prontuários e registros hospitalares de câncer, de pacientes na faixa etária de 0 a 19 anos, com melanoma comprovado histologicamente e atendidos entre 1997 e 2017 no Hospital Erasto Gaertner em Curitiba-PR. Resultados: amostra composta por 24 pacientes, sexo feminino (62,5\%), média de 14,12 $\pm 4,72$ anos de idade, com melanoma em cabeça e pescoço (37,5\%), tórax (25\%) e extremidades $(20,8 \%)$. Os sinais e sintomas ao diagnóstico foram aumento do tamanho da lesão (25\%), sangramento $(20,8 \%)$ e prurido $(16,6 \%)$. Ocorreu Índice de Breslow II e IV e Nível de Clark IV, com tendência estatística entre Breslow IV e óbito $(p=0,127)$ e significância entre Clark $V$ e óbito $(p=0,067)$. Nove $(37,5 \%)$ pacientes apresentaram metástases, seis $(25 \%)$ com metástases à distância morreram $(p=0,001)$, cinco eram meninas $(20,8 \%)$. A cirurgia foi o tratamento padrão e a quimioterapia o adjuvante mais utilizado (37,5\%). A média de tempo entre diagnóstico e óbito foi de 1,3 $\pm 1,2$ anos e de sobrevida foi 3,7 $\pm 3,2$ anos. Conclusão: houve atraso no diagnóstico, alta morbimortalidade e média de sobrevida menor do que cinco anos.
\end{abstract}

Palavras chave: Melanoma. Crianças. Linfonodo Sentinela. Análise de Sobrevida.

\section{REFERENCES}

1. Paradela S, Fonseca E, Pita-Fernández S, Kantrow SM, Diwan AH, Herzog C, et al. Prognostic factors for melanoma in children and adolescents: a clinicopathologic, single-center study of 137 Patients. Cancer. 2010;116(18):4334-44.

2. Instituto Nacional do Câncer (INCA) [Intenet]. [Brasília, DF]. Câncer de pele me-lanoma; 2018 [citado 2020 Jan 08]. Disponível em: https://www.inca.gov.br/ tipos-de-cancer/cancer-de-pele-melanoma.

3. Cordoro KM, Gupta D, Frieden IJ, McCalmont T, Kashani-Sabet M. Pediatric melanoma: results of a large cohort study and proposal for modified $A B C D$ detection criteria for children. J Am Acad Dermatol. 2013; 68(6):913-925.

4. Xu JX, Koek S, Lee $S$, Hanikeri M, Lee M, Beer T, Saunders C. Juvenile melanomas: Western Australian Melanoma Advisory Service experience. Australas J Dermatol. 2017;58(4):299-303.

5. Averbook BJ, Lee SJ, Delman KA, Gow KW, Zager JS, Sondak VK, et al. Pediatric melanoma: Analysis of an international registry. Cancer. 2013;119(22):40124019.

6. Saiyed FK, Hamilton EC, Austin MT. Pediatric melanoma: incidence, treatment, and prognosis. Pediatric Health Med Ther. 2017;8:39-45.

7. Strouse JJ, Fears TR, Tucker MA, Wayne AS. Pediatric melanoma: risk factor and survival analysis of the surveillance, epidemiology and end results database.
J Clin Oncol. 2005; 23(21):4735-474

8. Saenz N, Saenz-Badillos J, Busam K. Childhood melanoma survival. Cancer.1999;85(3):750-754.

9. Wong JR, Harris JK, Rodriguez-Galindo C, Johnson $\mathrm{KJ}$. Incidence of childhood and adolescent melanoma in the United States: 1973-2009. Pediatrics. 2013;131(5):846-854.

10. Brecht IB, De Paoli A, Bisogno G, Orbach D, Schneider DT, Leiter $U$, et al. Pediatric patients with cutaneous melanoma: A European study. Pediatr Blood Cancer. 2018;65(6):e26974.

11. Ferrari A, Bisogno $G$, Cecchetto $G$, Santinami $M$, Maurichi $A$, Bono $A$, et al. Cutaneous melanoma in children and adolescents: the Italian rare tumors in pediatric age project experience. J. Pediatr. 2014;164(2):376-382.

12. Stefanaki C, Chardalias L, Soura E, Katsarou A, Stratigos A. Paediatric melanoma. JEADV. 2017;31(10):1604-15.

13. Moscarella E, Zalaudek I, Cerroni L, Sperduti I, Catricalà C, Smolle J, et al. Excised melanocytic lesions in children and adolescents - a 10 - year survey. $\mathrm{Br} J$ Dermatol. 2012;167(2):368-373.

14. Dean PH, Bucevska M, Strahlendorf C, Verchere C. Pediatric Melanoma: A 35-year Populationbased Review. Plast Reconstr Surg Glob Open. 2017;5(3):1252-58.

15. Austin MT, Xing Y, Hayes-Jordan AA, Lally KP, Cormier JN. Melanoma incidence rises for children and adolescents: An epidemiologic review of 
pediatric melanoma in the United States. J Pediatr Surg. 2013;48(11):2207-2213.

16. Eggen $C A M$, Durgaram $V V L$, van Doorn $R$, Mooi WJ, Pardo LM, Pasmans SGMA, et al. Incidence and relative survival of melanoma in children and adolescents in the Netherlands, 1989-2013. J Eur Acad Dermatol Venereol. 2018;32(6):956-961.

17. Kim J, Sun Z, Gulack BC, Adam MA, Mosca PJ, Rice $H E$, et al. Sentinel lymph node biopsy is a prognostic measure in pediatric melanoma. J Pediatr Surg.
2016;51(6):986-990.

18. Al-Himdani S, Naderi N, Whitaker IS, Jones NW. An 18-year Study of Malignant Melanoma in Childhood and Adolescence. Plast Reconstr Surg Glob Open. 2019;30;7(8):2338-41.

19. Neves JM, Duarte B, Paiva Lopes MJ. Pediatric Melanoma: Epidemiology, Pathogenesis, Diagnosis and Management. SPDV [Internet]. 2020Jul.14 [cited 20200ct.22];78(2):107-14. Available from: https:// revista.spdv.com.pt/index.php/spdv/article/view/1197
Received in: 16/01/2020

Accepted for publication: 01/04/2020

Conflict of interest: no.

Funding source: none.

\section{Mailing address:}

Kátia Sheylla Malta Purim

E-mail: kspurim@gmail.com

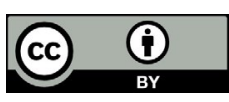

